Brock Education

Vol. 13, No. 1, 2003

\title{
Language Awareness in Nova Scotia Schools: An Exploratory Study
}

\author{
David Piper
}

Acadia University

\begin{abstract}
The author conducted a questionnaire survey of language awareness in 358 students studying in Grades 8, 10, and 12 English classes in three rural and three urban schools in Nova Scotia. The main objectives of the study were to learn just how sensitive these students were to key aspects of language prior to any deliberate instruction in language awareness, to obtain new information about levels of natural language awareness as the basis for curriculum development, to uncover significant subject variables in relation to developing language awareness, and to clarify the theoretical distinction between "ordinary" and "critical" language awareness.
\end{abstract}

In his book Awareness of Language: An Introduction, Eric Hawkins (1984), reflected a growing recognition of the educational value of curriculum development and teaching designed to enhance students' metacognitive knowledge about language and communication. For Hawkins, one purpose of teaching for language awareness was to "light fires of curiosity about the central human characteristics of language" and to "make our students' contacts with language...richer, more interesting, and simply more fun." He also viewed language awareness as an antidote to "linguistic complacency" and as a means of heightening students' sensitivity towards the relationship between language use, prejudice, and discrimination (Hawkins, 1984, p. 6).

In the 1990s, the influence of critical theorists like Bourdieu, Foucault, and Habermas, together with a rise in understanding about the close relations between language and cultural identity, led to an evolutionary movement in the field of language education from a concentration on language awareness (LA) to one on critical language awareness (CLA). As a new introduction to the field by Norman Fairclough (1992) established, this was a move away from a mere

David Piper teaches educational psychology and applied linguistics at Acadia University in Wolfville, Nova Scotia. His main scholarly interests include language awareness, the development of selfhood and identity, and transformative educational practice. 
interest in language patterning, or even in the dynamics of everyday language functions, and towards more political awareness of "how language conventions and language practices are invested with power relations and ideological processes" (Fairclough, 1992, p. 7). In a series of theoretical propositions, Fairclough set forth several key educational objectives for critical language awareness. The most general of these was to establish an understanding of language as discourse that both shapes and is shaped by society. This, he believed, would help to foster an understanding of how language plays a central role in the formation of ideological positions and relations of power (1992, p. 8-9).

While the general educational principles and practices relating to teaching for the various levels of language awareness are now well-established, there may be some danger in assuming that children are fundamentally unaware of variations in language before they encounter formal language awareness classes in schools. Several good reasons exist as to why some research on this question might be of value to the field of language education. One reason is the likelihood that students may already be sensitive to various forms of language variation and communicative intent. We might assume falsely, for example, that children are unable to make critical judgements about language in advertising or other media discourses because we lack sufficiently detailed knowledge about how they actually process the language around them. It is even possible that there may be some significant contrasts in qualities of language awareness that are due to generational differences between students and their teachers.

A second reason is that if levels of language awareness are a quite normal part of children's linguistic and social development, then it would be useful to know as much as we can about these developmental processes in order to think with greater precision about appropriate curriculum for language awareness. A third reason is that a more detailed understanding about any significant relationships between aspects of children's natural language awareness and any relevant background variables (such as gender, age, and so on) should provide important grounding for making specific curriculum adaptations within particular language communities. A fourth reason is that understanding natural levels of language awareness that are developed without specific teaching input should help us to clarify the important theoretical distinction between what might be considered to be "ordinary" and truly critical language awareness. A final reason, following Corson's (1997, 1999) advice on the development of language policies in schools, is that there is great value in conducting research and assessment in the contexts of localized discourse communities. One emergent theme in language education is the growing recognition that the essence of human communication lies in the continual and 
creative development of language forms and functions within language communities. As Corson (1999) points out, research undertaken in local communities should lead to important insights for heightening teachers' language awareness in relation to the communicative and academic needs of their students.

This paper reports an exploratory study of children's natural language awareness conducted with the goal of achieving such insights. A survey was conducted of students in Grades 8, 10, and 12, studying in both rural and urban schools in Nova Scotia. The main purposes of the study were to explore students' levels of language awareness and to generate further interesting questions about the relationship between language awareness and teaching practice.

\section{Method}

\section{Questionnaire Development}

Language awareness involves a number of different and quite specific kinds of knowledge about language. At one level, it involves knowledge about structure and grammar and, at another, knowledge about social aspects of language, including language variation, speaker and audience variability, language functions, speaker intent, and contextual code-switching. At a third and even higher level, it involves knowledge about how language can be deliberately manipulated for persuasive effect, a process which most typically takes place in advertising contexts. At the highest level of all, the level of critical language awareness, the focus is on recognition of how social and discourse patterns are mutually constitutive and of how individuals are largely immersed in and conditioned by the language patterns of communities at large.

The study focused on exploring language awareness at the first three of the above four levels (grammatical awareness, sociolinguistic awareness, and advertising awareness). In order to find out more about natural levels of awareness in these various categories, I set out to develop a questionnaire that could be presented in language classrooms as a quite natural (if not regular) part of classroom work in English. From the outset, the intent was to design a questionnaire that would be of interest to students in grades 8,10 , and 12, and that they would not construe as some kind of objective test. For this reason, rather than calling it a "research instrument to determine language awareness," I constructed the questionnaire in the more familiar style of surveys students would likely know from reading popular magazines. The questionnaire bore the title: "How sensitive are you about language?" 
The questionnaire was divided into five main sections, each of which was designed to yield observations about the relationship between the independent subject-background variables and dependent measures of subjects' language awareness. In the first section, students were required to provide data on each of the following: a) gender, b) grade level, c) time spent watching television, d) time spent on computers and the Internet, and e) time spent reading for enjoyment. In the context of this limited exploratory study, however, it was felt that these were promising initial items on which to build further research and analysis.

In the second section, targeting grammatical awareness, students were asked to respond to the general question, "How sensitive are you about the mistakes people make in using language?" Here students were asked to make judgements about a series of expressions which were either grammatical in form or which contained some well-known error. Examples included: The school principal spoke to the parents (correct), Celine Dion is a more better singer than Shania Twain (incorrect duplicate comparative), and Brad Pitt is act in a new movie (incorrect verb phrase). In addition to circling "right" or "wrong" for each expression, students were further invited, if they felt like it, to circle the place in the expression where any mistake occurred.

In the third section, targeting sociolinguistic awareness, students were asked to try to recognize a variety of English accents. They listened to six recorded examples of English accents featuring speakers from a) the Southern United States, b) Nova Scotia, c) Jamaica, d) Southern England, e) Australia, and f) a northern Canadian (Inuit) region.

In the fourth section, also on sociolinguistic awareness, students were asked to listen to some further speech examples that had been recorded by a number of university linguistics students who volunteered for the study and who possessed both good acting abilities and sophisticated levels of language awareness. These samples were all based on dialogues between a young adult male and a young adult female whose language use was systematically varied to reveal distinctions between informal and formal English and key distinctions in speaker intent. Three communicative situations were used-a wedding, an office meeting, and a cooking class-yielding six dialogues (wedding formal/ informal; meeting formal/informal; cooking class formal/informal). Following the general question "Can you recognize the language people use in different situations?" students were asked to judge whether they thought the speakers were using language informally, formally, or very formally and whether the speakers' relationship to each other appeared to be very friendly, friendly, or not friendly. They were further asked to make judgements about aspects of the speakers' motivations. For example, in the two wedding party dialogues, 
students were asked whether they thought the male spoke in a way that suggested he did or did not want to get to know the female better and whether they thought the female was enthusiastic or otherwise about the male. In the two cooking class dialogues, subjects were given choices about the nature of the relationship between teacher and student, and in the meeting dialogues they were asked to make judgements about the extent of agreement achieved between the speakers. In order to bring as much content-validity as possible to these dialogues, they were developed through several trials and subjected to prior evaluation by student teachers taking the same course in Applied Linguistics.

Finally, in the fifth section, which explored students' advertising awareness, students were asked to respond to some questions about two genderbased advertisements selected from popular magazines. In the first advertisement, designed to persuade readers to join the armed forces, the head and shoulders of a young woman in the uniform of the United States Marines were portrayed, together with the following caption:

You can change the shade of your lipstick, or you can change your life. Because the changes you make on the inside are the ones that will last forever. Changes that build character. Take you further. Get a make-over that's more than skin deep.

In the second advertisement, designed to persuade readers to buy Preferred Stock cologne, the head of a young man is portrayed juxtaposed to the text:

Preferred Stock: What Preferred Men Prefer-a Man's Cologne from the House of Stetson.

As a basis for developing measurements of subjects' language awareness in response to these advertisements, the texts received prior evaluation, once again, from the 25 students in the linguistics class. Following discussion, multiple-choice questions were developed for the survey designed to test students' abilities to make judgements about the use of certain key words. An example from the Marines' advertisement was the word lipstick, and students were asked to select from the following alternative readings:

The word LIPSTICK is used (Circle a letter)

a .to suggest that women are generally feminine and weak.

b. to suggest that women are attractive when they wear make-up.

c. to suggest that women who use make-up are stronger and smarter.

d. all of the above. 
Similar interpretive choices were given for the keywords change and forever. In the case of the advertisement for cologne, keywords chosen were both preferred and stock, and questions explored subjects' awareness of the associations between these terms and ideas about masculinity and privilege. Again, measures were based on the judgements made by members of the linguistics class prior to the final design of the questionnaire.

\section{Survey Procedure}

In all, 358 students in a total of eighteen Grade 8, 10, and 12 classrooms across six schools (three urban and three rural) completed the survey. Classes were selected for research on the basis of their having no prior experience of direct instruction in language awareness. Before completing the questionnaires, students were informed that they would be participating in an objective survey on sensitivity to language, and that no academic assessment would be based on their responses. They were told not to place their names on the response booklets, and that all responses were voluntary and confidential. All sections of the questionnaire were read out loud to students by a research assistant, and students were able to follow the text themselves. Time to complete each section was flexible and, as promised at the outset, time was also provided at the end of each class for discussion about any questions students might have about the survey or about language in general.

\section{Data Analyses and Findings}

In preparation for statistical analysis, the independent background data were coded, and scores were assigned for the dependent measures of performance for grammatical awareness, sociolinguistic awareness, and advertising awareness. The data were then analyzed using a number of regression techniques. In a first analysis, the general relationship between the subject (independent) variables and subjects' total scores for language awareness were collapsed across the three awareness subcategories. The regression coefficients for the analysis of total scores revealed a highly significant general relationship between dependent and independent variables $(F=14.526 ; p<.001)$ suggesting, in very general terms, that the data on subjects' backgrounds could be used to predict variations in the dependent measures in a reliable and powerful manner. This first overall analysis also revealed that the best predictors of overall score in language awareness were, in order of significance, grade level $(F=5.5 ; p<.001)$, reading frequency $(F=4.47 ; p<.001)$, and computer use $(F=3.5 ; p<.01)$. 
Following this, several separate multiple regression analyses of variance (ANOVAs) were performed on the independent measures and each of the dependent variable categories taken in turn. The second analysis, on grammatical awareness, also revealed a measure of overall significance, together with gender and residential area (urban vs. rural) as the best predictors of performance. The third analysis, on sociolinguistic awareness, yielded an indication of overall significance, together with grade level, reading frequency, and computer use as the main predictors. Finally, a fourth analysis, on advertising awareness, also yielded a measure of overall significance together with reading frequency as the main predictor of success (in significant effects reported here, $p<.01$ ).

To explore the meaning of the results, further post-hoc Tukey tests were performed on mean scores. From this, several interesting findings emerged: First, an interaction appeared in which, while Grade 8 and 10 students in the urban schools obtained higher overall scores than their counterparts in the rural schools, the rural school students scored higher than urban students in Grade 12.

Table 1 - Mean (rounded) percentage scores for overall language awareness: Grade Level and Area of Residence

$\begin{array}{lccc}\text { Area } & \text { Grade } 8 & \text { Grade } 10 & \text { Grade } 12 \\ \text { Rural } & 58 & 59 & 70 \\ \text { Urban } & 60 & 62 & 66\end{array}$

Second, reflecting a well-recognized pattern in language education, girls showed more language awareness in the lower two grades, but were about equal to boys by Grade 12. More detailed analysis showed, however, that grammatical awareness was the major contributor to this effect.

Table 2 - Mean percentage scores for overall language awareness: Gender and Grade Level

\begin{tabular}{|c|c|c|c|}
\hline Gender & Grade 8 & $\underline{\text { Grade } 10}$ & Grade 12 \\
\hline Male & 52 & 58 & 67 \\
\hline Female & 56 & 63 & 69 \\
\hline
\end{tabular}


Perhaps surprisingly, the boys in the study, living in both rural and urban areas, scored higher than the girls for sociolinguistic awareness (accent recognition and contextual analysis combined).

Table 3 - Mean percentage scores for sociolinguistic awareness: Gender and Grade Level

\begin{tabular}{|c|c|c|c|}
\hline Gender & Grade 8 & $\underline{\text { Grade } 10}$ & Grade 12 \\
\hline Male & 54 & 60 & 72 \\
\hline Female & 48 & 58 & 64 \\
\hline
\end{tabular}

One other finding of interest was that boys who reported higher amounts of television-watching and computer-use also scored higher for advertising awareness, while quite the opposite effect appears true for girls.

Table 4 - Mean percentage scores for advertizing awareness: Gender and Time reported spent with media (television-watching and computer-use combined)

$\begin{array}{lcc}\text { Gender } & \text { Less than } 10 \text { hours } & \frac{\text { More than } 14 \text { hours }}{\text { Male }} \\ \text { Female } & 55 & 62 \\ 64 & 52\end{array}$

\section{Discussion}

Overall, the results suggest that students come to their English classes with many kinds of language awareness in place. The purpose of the questionnaire survey was exploratory; its most important contribution lies in suggesting lines of further inquiry, in promoting further meaningful questions about approaches to language awareness in classrooms and schools, and, following Corson's (1999) proposals for justifying the development of language policies in schools, in gauging what can be learned from the actual practice of conducting language awareness research in a given language community (Nova Scotia).

In keeping with the intentions, the survey raised a number of questions for further research about the particular patterns of natural language awareness in these students. Considering the responses as a whole, it appears that school students develop in language awareness as a quite natural part of their cognitive and social development. The study also suggests, though, that English classes focused on language awareness enhance the varieties of students' language 
experiences and thus support their developing awareness. One interesting related question for further research concerns the different sociolinguistic contexts of rural and urban areas in relation to the variety of students' language experiences. Could it be, for instance, that rural students' language awareness might be enhanced by ensuring greater exposure to the broader range of language varieties and communicative intentions found in urban settings? Another question concerns the relationship between children's experiences with the media, including television and computer-based communications, and their language awareness. The findings in the study also suggest that some further research is needed on how best to integrate work on language awareness with children's explorations in virtual communicative contexts on the Internet. It seems possible that children's experiences in the virtual communities of cyberspace may provide rich sources for the development of language awareness. Yet other interesting questions centre on possible differences in style and communication between generational language communities (i.e., teachers and their students, and on the different ways in which girls and boys respond to, interpret and utilize information gained from watching television and using computers.

Although each of these specific questions might lead to worthwhile lines of research in the future, some of the indirect findings from the research may have as much significance for developing curriculum in language awareness. Two common observations made by those collecting the research data were of the genuine interest of many students in exploring these aspects of language awareness and of the overall sharpness of their observations about the complex relations between language, identity, and speaker-intent. From the perspective of curriculum development for language awareness, these interactions, together with the overall scores in the survey, leave little doubt that teachers have a rich and natural base of student background knowledge and interest to work with.

In his summary of some of the current main objectives in teaching practice for language awareness, Corson (1999) identified nine central "areas of knowledge," including knowledge of the patterns of language, different styles or varieties within students' own language, knowledge that other varieties of their own languages are used in different societies (or dialect areas), and knowledge about the use of different styles of English for different purposes (Corson, 1999, p. 135-142). The survey results in this study suggest that many students in Nova Scotia's schools are already knowledgeable in many of these areas and that their growing awareness about language provides a rich base for curriculum development and teaching. The findings also suggest that researchers are likely to find certain significant subject variables within each language community 
studied-variables such as gender and area of residence-that can be seen to affect levels and rates of development in language awareness.

Finally, the question remains about the relationship between the foundation of students' natural development of language awareness and later teaching for critical language awareness. This study suggests that many students already have levels of language awareness that are prerequisite to higher and more critical levels of response. It also raises the question of how "critical" language awareness should be distinguished from the so-called lower levels of language awareness. A detailed treatment of this question lies beyond the scope of this exploratory survey, but a satisfactory answer would seem to depend, among other things, on a more precise definition and understanding of what the term "critical" actually means in this context. As this study suggests, many students already have a natural ability to recognize at least some of the ways in which advertisers make deliberate language choices as part of their techniques of persuasion. In this way, it seems that the students are already sensitive to some of the ways in which language can be deliberately manipulated for effect. What remains to be explored, however, is just how this kind of language awareness provides the basis for the further cognitive leap into awareness of the more complex relations between language, identity, and social organization.

Perhaps the most significant question of all, though, is that of whether one can claim that a level of "critical" language awareness can be fully distinguished over and above the kinds of language awareness explored in this study. If "critical" is to be understood as a form of politically-oriented language awareness (Fairclough, 1992), then a pedagogical contradiction arises: On the one hand, education for language awareness is motivated by an interest in opening up new questions about relations between language, identity, and society but, on the other, the view of language as essentially "political" in nature brings with it its own forms of conceptual foreclosure. The latter danger is particularly apparent in "critical pedagogical" approaches to language awareness, in which the interpretation of "political" is already infused with connotations of "resistance" and "liberation." This study suggests that there may be more to be gained in language education by exploring actual levels of language awareness in particular communities, and by building on these levels, rather than by introducing conceptualizations of "critical" language awareness that themselves give rise to skepticism and doubt. 


\section{References}

Corson, D. (1997). Awareness of non-standard varieties in the schools. In L. van Lier \& D. Corson (Eds.), Knowledge about language: Encyclopedia of language and education (Vol.6) (pp. 229-240). Dordrecht: Kluwer Academic Publishers.

Corson, D. (1999). Language policy in schools: A resource for teachers and administrators. Mahwah, NJ: Lawrence Erlbaum Associates.

Fairclough, N. (Ed.). (1992). Critical language awareness. London, England: Longman.

Hawkins, E. (1984). Awareness of language: An introduction. Cambridge: Cambridge University Press. 